\title{
Conteúdo ou forma? Um estudo sobre a influência da familiaridade com a linguagem pictórica e o conteúdo informacional na compreensão de seqüência pictórica de procedimento.
}

\author{
Contents or shape? Considerations about the effects of familiarity with informational \\ contents and graphic language in understanding a procedural pictorial sequence.
}

seqüência, familiaridade, conteúdo, representação pictórica

O objetivo deste trabalho foi verificar qual fator é mais influente na compreensão de uma SPP sobre o uso do preservativo masculino - se a familiaridade com o conteúdo pictórico ou com a linguagem gráfica. Após a apresentação dos dados e sucinta discussão, veremos que a familiaridade com o conteúdo representado graficamente favorece a compreensão da SPP mais do que a familiaridade com a linguagem pictórica utilizada.

sequence, familiarity, contents, pictorial representation

The aim of this research was to verify which factor influences the comprehension of a PPS about the use of the condom the most - if the familiarity with the informational contents or the familiarity with the graphic language. After the presentation and brief discussion of the results, we will see that the familiarity with the graphically represented contents favour the comprehension of the PPS more than the familiarity with the used pictorial language.

\section{Introdução}

Os dados apresentados neste artigo são provenientes de monografia de conclusão de curso em Design pela Universidade Federal de Pernambuco (Maia, 2005), sendo discutidos os efeitos da familiaridade com o conteúdo pictórico e com a linguagem gráfica na compreensão de seqüência pictórica de procedimento (SPP).

Instruções acompanham diversos tipos de bens, podem ser encontradas em produtos de diversas naturezas, incluindo materiais educativos e/ou informativos da área de saúde. A possibilidade de utilização de uma instrução é bastante abrangente; podemos encontrá-la em materiais que visam educar a população a respeito de doenças ou até em materiais que procuram divulgar métodos contraceptivos.

As duas principais maneiras de apresentação de instruções são a textual e a pictórica. Apesar de instruções textuais serem veiculadas com maior freqüência (Zimmerman \& Perkin, 1982), a importância da instrução pictórica é enorme, principalmente quando levamos em consideração aspectos econômicos e sociais. Ao contrário da informação textual, a representação de instruções por ilustrações pode atingir tanto o público com grau de instrução alto como aquele sem nenhum ou com baixo grau de instrução. É a partir da necessidade de se comunicar uma mensagem a segmentos diversos da população que se tem explorado o uso da linguagem pictórica para serem veiculadas advertências, comunicações de risco e informações relacionadas à segurança (Wogalter et al., 1997).

Segundo Spinillo (2000), SPPs são representações de instruções por meio de ilustrações. De acordo com a autora, o seu conteúdo informacional pode ser dividido em processual (passos) e não-processual (como proibições ou precauções). É pelo uso de SPPs que muitas vezes se pretende transpor barreiras, como a da linguagem, na transmissão de informação. No entanto, muitos aspectos relativos à compreensão da linguagem pictórica ainda precisam ser investigados.

De acordo com Brody (1981), pressões sociais como demanda, interesse crescente em instrução individualizada, apoio financeiro reduzido e população estudantil cada vez mais 


\section{Infodesıgn}

heterogênea têm aumentado a necessidade de otimização das pesquisas sobre instruções visuais.

O autor aponta falhas nos estudos realizados sobre imagens utilizadas em textos de instrução, destacando que muito se tem investigado, mas pouco ainda se sabe sobre o aprendizado a partir de ilustrações.

\section{Familiaridade com o objeto representado}

Aspectos culturais afetam a percepção de estímulos visuais de um indivíduo (AjayiDopemu, 1982; Mangan, 1978). Segundo Pettersson (1982), o que é percebido num campo visual, e a maneira como o conteúdo de uma imagem é interpretado, depende da condição de familiaridade do observador com a imagem e se a interpretação adequada dessa imagem tem valor de sobrevivência dentro de sua cultura. Para reconhecer uma representação e entender a mensagem transmitida, é necessário que a pessoa conheça o objeto representado (Mangan, 1978; Hochberg \& Brooks apud Levie, 1978; Levie, 1978).

Se os objetos representados não forem familiares à audiência à qual se destina, as pessoas podem não se interessar pelo conteúdo da imagem, além de serem provavelmente pouco capazes de reconhecer o tema representado. Nesse caso, o observador pode tentar adivinhar seu significado através de uma impressão geral ou se ater a detalhes irrelevantes, que levem a uma compreensão equivocada da figura (Jenkins, 1978).

A natureza do objeto representado num pictograma é relevante quando se verifica o nível de compreensão da mensagem (Wogalter et al. 1997). As representações pictóricas melhor compreendidas tendem a ter um caráter mais concreto, enquanto as de caráter mais abstrato conseguem comunicar a mensagem adequadamente a um número reduzido de leitores.

\section{Familiaridade com o modo de representação}

É necessário também que a audiência possua familiaridade com o modo de representação (Seldon apud Ajayi-Dopemu, 1982; Jenkins, 1978), e sejam respeitadas as tradições de representações gráficas da sua comunidade (Zimmerman \& Perkin, 1982).

Não se pode esperar que pessoas diferentes vejam a mesma coisa em representações pictóricas, pois a percepção de cada uma é determinada pela bagagem cultural adquirida (Mangan, 1978). Participantes analfabetos não necessariamente observam uma seqüência de imagens da esquerda para a direita, ou assumem que haja uma conexão entre os quadros da seqüência (Fussell e Haaland, 1978). Porém, essa forma de narrativa (como a de quadrinhos) tem sido muito utilizada na educação não formal de diversos setores da população mundial, pois são altamente atrativos e fáceis de serem compreendidos (Jenkins, 1978).

Por outro lado, certas convenções pictóricas distorcem a realidade e podem causar confusão no observador que não esteja familiarizado com o modo de representação. Convenções utilizadas em histórias em quadrinhos podem ser difíceis de serem compreendidas. Mesmo que o observador entenda que os quadros dispostos em seqüência formam uma história, têm ligação entre si ou descrevem um evento, erros de interpretação podem ocorrer (Jenkins, 1978).

\section{Materiais e métodos}

Foram entrevistados 40 estudantes universitários que tivessem familiaridade com a linguagem pictórica ou com o conteúdo pictórico contido na SPP estudada.

Os participantes foram divididos em dois grupos, cada um com 20 estudantes (10 homens e 10 mulheres): (a) estudantes do curso de Design com familiaridade com a linguagem gráfica utilizada na instrução; (b) estudantes de medicina com familiaridade com o conteúdo informacional da SPP. Os sujeitos foram escolhidos aleatoriamente e agrupados de acordo com o curso no qual estavam matriculados.

Para a coleta de dados foi utilizado um questionário semi estruturado. A cada participante foi entregue uma SPP e um questionário que deveria ser respondido individual e isoladamente. 
Figura 1: SPP sobre o uso do preservativo masculino produzida e distribuída pelo Ministério da Saúde

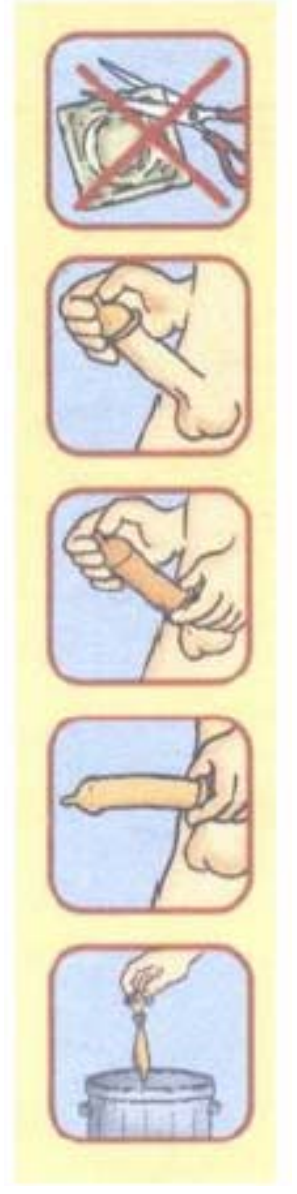

A SPP utilizada no estudo (Figura 1) apresenta a tarefa de colocar o preservativo masculino em 4 passos e 1 advertência (5 quadros):

- Advertência: Tire a camisinha do pacote só na hora de usar. Não use os dentes nem objetos cortantes (tesoura, faca).

- Passo 1: Aperte a ponta para tirar o ar e coloque a camisinha no pênis quando ele estiver duro.

- Passo 2: Desenrole a camisinha até a base do pênis.

- Passo 3: Tire a camisinha depois que gozar, mas enquanto o pênis estiver duro. Segure na borda para o esperma não vazar.

- Passo 4: Dê um nó na camisinha e jogue no lixo.

\section{Tabulação e análise de dados}

Para análise dos dados, utilizou-se um sistema de classificação de respostas que tinha como referência a instrução textual da cartilha (Figura 1). As respostas foram classificadas de acordo com o correspondente descrito na mesma.

(C) Compreendeu - resposta de acordo com o descrito na instrução;

(CP) Compreendeu Parcialmente - resposta parcialmente de acordo com o parâmetro estabelecido;

(NCRI) Não Compreendeu ou deu Resposta Inadequada - resposta em desacordo com o descrito na instrução. 


\section{Infødesıgn}

\section{Resultados e discussão}

Foram comparados os dados fornecidos pelos questionários, para verificar qual fator de familiaridade possui maior influência na compreensão da SPP: a familiaridade com a linguagem pictórica ou com o conteúdo processual.

Tabela 1: Grupo 1 - Alunos de Design; Grupo 2 - Alunos de Medicina; [C] Compreendeu; [CP] Compreendeu Parcialmente; [NCRI] Não Compreendeu ou deu Resposta Inadequada; [NR] Não respondeu

\begin{tabular}{l|l|l|l|l|l} 
& & {$[\mathrm{C}]$} & {$[\mathrm{CP}]$} & {$[\mathrm{NCRI}]$} & {$[\mathrm{NR}]$} \\
\hline \multirow{2}{*}{ Advertência } & Grupo 1 & $31,25 \%$ & $56,25 \%$ & $6,25 \%$ & $6,25 \%$ \\
\cline { 2 - 6 } & Grupo 2 & $30 \%$ & $70 \%$ & - & - \\
\hline Passo 1 & Grupo 1 & - & $100 \%$ & - & - \\
\cline { 2 - 6 } & Grupo 2 & $30 \%$ & $55 \%$ & $15 \%$ & - \\
\hline Passo 2 & Grupo 1 & $18,75 \%$ & $56,25 \%$ & $25 \%$ & - \\
\cline { 2 - 6 } & Grupo 2 & $10 \%$ & $85 \%$ & $5 \%$ & - \\
\hline Passo 3 & Grupo 1 & - & $31,25 \%$ & $56,25 \%$ & $12,5 \%$ \\
\cline { 2 - 6 } & Grupo 2 & - & $45 \%$ & $45 \%$ & $10 \%$ \\
\hline Passo 4 & Grupo 1 & $56,25 \%$ & $43,75 \%$ & - & - \\
\cline { 2 - 6 } & Grupo 2 & $70 \%$ & $30 \%$ & - & - \\
\hline
\end{tabular}

De maneira geral, os estudantes de medicina compreenderam melhor a instrução pictórica que os de design. Aparentemente, a familiaridade que os participantes do segundo grupo têm com o conteúdo processual contribuiu para que eles conseguissem ter uma idéia geral mais apurada do processo de colocação e retirada do preservativo.

O que caracterizou o desempenho dos alunos de medicina é que, mesmo não especificando ou detalhando os dados fornecidos, mostraram um domínio maior que o primeiro grupo a respeito do procedimento. Assim, foram mais objetivos na descrição das representações, o que não significa um menor nível de compreensão. Os alunos que possuíam familiaridade com o conteúdo informacional demonstraram compreender melhor a SPP, abrangendo todos os passos e aspectos relativos à execução adequada da tarefa. Quando questionados a respeito de elementos ou detalhes específicos, o desempenho baixou um pouco, mas ainda assim, deram sinais de que desempenhariam a tarefa corretamente.

Podemos sugerir que, no caso de um público familiarizado com o conteúdo de uma representação pictórica seqüenciada, as ilustrações não irão agir como agente educador - o leitor familiarizado com a informação não irá aprender novas coisas a partir da SPP. Ao invés disso, a SPP agiria como guia, dando orientações básicas ao leitor e o auxiliando a acessar as informações que já possui.

Apesar dos alunos de design terem reconhecido os elementos representados, a mensagem transmitida pelas figuras não foi bem compreendida. Devido ao alto número de respostas parcialmente corretas de acordo com a instrução textual, podemos inferir que os participantes do grupo 1 conseguiram situar os passos dentro da tarefa, mesmo não tendo feito descrições tão precisas das etapas do procedimento.

Os participantes que possuíam familiaridade com a linguagem pictórica dependiam muito mais dela para compreender a tarefa que os participantes com familiaridade com o conteúdo processual. Como dito anteriormente, esses últimos utilizavam as ilustrações para acessar uma informação aprendida anteriormente, e não aprendiam a partir delas. Já os alunos de design dependiam mais das ilustrações para a descrição correta dos procedimentos.

\section{Agradecimento}

Às Profas. Dras. Stephania Padovani, pela orientação e Carla G. Spinillo, pelo apoio. Ao CNPq pela bolsa de iniciação científica. 


\section{Referências}

Ajayi-Dopemu, Y. (1982). Visual aids and the enhancement of communication in Africa. Journal of Educational Television, 8, 3, pp. 203-209.

Brody, P. J. (1981). Research on pictures in instructional texts: the need for a broadened perspective. ECTJ, 29, 2, pp. 93-100.

Fussel, D. \& Haaland, A. 1978. Communicating with pictures in Nepal: results of practical study used in visual education. Educational Broadcasting Internationall,11, 1, pp. 25-31.

Jenkins, J. (1978). Using pictures in non-formal education. Education Broadcasting International, 11, pp. 32-38.

Levie, W. H. (1978). A prospectus for instructional research on visual literacy. ECJT, 26, 1, pp. 25-36.

Maia, T. C. (2005). Efeitos do grau de escolaridade e da familiaridade na compreensão de seqüência pictórica de procedimento. Monografia de conclusão de graduação. Universidade Federal de Pernambuco.

Mangan, J. (1978). Cultural conventions of pictorial representation: iconi lietarcy and education. Educational communication \& Technology, 26, 3, pp. 245-267.

Pettersson, R. (1982). Cultural differences in the perspective of image and color in pictures. ECTJ, 30, 1, pp. 43-53.

Wogalter, M. S., Sojourner, R. J. \& Brelsford, J.W. (1997). Comprehension and retention of safety pictorials. Ergonomics, 40, 5, pp. 531-542.

Spinillo, C. (2000). An analytical approach to procedural pictorial sequences. PhD Thesis. Department of Typography \& Graphic Communication, The University of Reading.

Zimmerman, M.L. \& Perkin, G.W. (1982). Instructing through pictures: print materials for people who do not read. Information Design Journal, 3, 2, pp. 119-134.

\section{Sobre o autor}

Tiago Costa Maia concluiu o curso de Design pela Universidade Federal de Pernambuco em 2005 e foi bolsista de iniciação científica por dois anos. 